\title{
Aqueous Phase Separation Behavior of Highly Syndiotactic, High Molecular Weight Polymers with Densely Packed Hydroxy- Containing Side Groups
}

Dorette S. Tromp, Marianne Lankelma, Hannah de Valk, Emile de Josselin de Jong, and Bas de Bruin*(C)

Van 't Hoff Institute for Molecular Sciences (HIMS), Department of Homogeneous and Supramolecular Catalysis, Universiteit van Amsterdam, P.O. Box 94720, 1090 GS Amsterdam, Netherlands

\section{Supporting Information}

ABSTRACT: Herein we describe the Rh-catalyzed C1 polymerization of silyl-protected diazoacetates of the general formula $\mathrm{HC}\left(=\mathrm{N}_{2}\right) \mathrm{C}(=\mathrm{O}) \mathrm{O}\left(\mathrm{CH}_{2}\right)_{x} \mathrm{OSiR}_{3}$, where $x=2-5$. After polymerization and subsequent desilylation, syndiotactic polymers bearing a hydroxy-containing side group on every backbone carbon are obtained. The molecular weight of the desired polymers can be controlled via chain transfer with methanol during the polymerization. The produced polymers are compared to atactic analogues formed by $\left[\left(\eta^{3}-\mathrm{C}_{3} \mathrm{H}_{5}\right)\right.$ $\mathrm{PdCl}$-catalyzed polymerization of silyl-protected diazoacetates with the same general formula. While the polymers produced by the $\mathrm{Rh}$ and $\mathrm{Pd}$ catalysts have the same hydrophilic/hydrophobic balance, the stereoregularity of the polymers formed by the Rh catalyst was found to be of influence on the thermoresponsive behavior of the polymer. The effect of this stereoregularity on the thermoresponsive phase separation behavior of the produced polymers in aqueous solution was investigated.

\section{INTRODUCTION}

Stimuli-responsive polymers are polymers that show changes in their chemical and/or physical properties in response to changes of their environment (stimuli), e.g. change in $\mathrm{pH}$, temperature, or exposure to light. One can imagine a myriad of applications for these polymers, and indeed they gained increasing attention in the biomedical (e.g. biosensing, ${ }^{1}$ controlled drug delivery, ${ }^{1-3}$ and imaging contrast agents ${ }^{4}$ ), bioengineering, and chemical fields (e.g. stabilization of colloids, ${ }^{6}$ oil-displacing agents, ${ }^{7}$ and catalyst supports ${ }^{8}$ ). Most polymers used in those fields are thermoresponsive polymers, which undergo a reversible phase transition when subjected to temperature changes. The temperature at which the phase transition in solution occurs is called the critical solution temperature. Polymers that become soluble as the temperature increases exhibit an upper critical solution temperature (UCST), and those that become insoluble with temperature increase exhibit a lower critical solution temperature (LCST). ${ }^{9}$ The most widely investigated thermoresponsive polymers with an LCST are poly( $N$-isopropylacrylamide) (PNIPAAM $),{ }^{2,5,8,10-13}$ poly(2-hydroxypropyl acrylate) (PHPA), ${ }^{14,15}$ poly(2-hydroxyethyl methacrylate) (PHEMA), ${ }^{16}$ and poly(vinyl ether)s. ${ }^{17-19}$ These polymers are obtained by (controlled) radical polymerization of polar functionalized alkenes, ${ }^{20}$ where the alkene bond of each monomer $(\mathrm{C}=\mathrm{C})$ delivers two carbon atoms in each chain growth step (C2 polymerization). However, this type of polymerization generally gives poor control over the tacticity of the polymers. Transition metal (TM) catalyzed polymerization is known to give access to highly stereoregular polymers, but many polar functional groups on the monomers are not compatible with existing catalysts in TM polymerization. This makes the preparation of well-defined, stereoregular, high molecular weight $\left(M_{\mathrm{w}}\right)$ polymers from polar functionalized C2 monomers very difficult. ${ }^{21,22}$ A new strategy for the synthesis of stereoregular, high molecular weight polymers is TMcatalyzed C1 (methylene or carbene) polymerization. This approach allows for the synthesis of stereoregular polymers that are functionalized with polar groups on every backbone carbon and is also a powerful tool to obtain polymers with a large structural diversity. ${ }^{23} \mathrm{Cu}^{24,25}$ and Pd-catalyzed ${ }^{26-32} \mathrm{Cl}$ polymerization reactions of diazoesters and diazoketones have been reported, but the low molecular weight and atacticity of the obtained polymers as well as the often observed random incorporation of azo groups are limitations of these catalyst systems. ${ }^{31,32} \mathrm{Rh}$-catalyzed $\mathrm{C} 1$ polymerization is more selective and gives access to high molecular weight and highly syndiotactic polymers with polar ester functionalities at every carbon atom of the polymer backbone. ${ }^{33-41}$

Recently, Ihara and co-workers published the synthesis of C1 analogues of PHEMA, PHEA (poly(2-hydroxyethyl acrylate)), and oligo(ethylene gycols) (OEGs) via palladium-

Received: $\quad$ May 31, 2018

Revised: August 20, 2018

Published: September 11, 2018 
catalyzed $\mathrm{C} 1$ polymerization of hydroxyl-containing diazoacetates. $^{42,43}$ The resulting polymers were expected to have unique properties such as high hydrophilicity and superior thermal and mechanical properties due to the denser packing of the substituents around the polymer chain. Indeed, the resulting polymers are soluble in water and show thermoresponsive behavior in aqueous media. However, the polymers have low $M_{w}$ and atactic structures. This work inspired us to investigate the polymerization of silyl-protected hydroxylcontaining diazoacetates using the stereospecific Rh catalyst I (Scheme 1). ${ }^{37,41}$ We wondered in particular what would be the

Scheme 1. Rh Precatalyst I ([(Allyl- $\beta$-Alkyl

Hydroxide $\left.\left.) \mathrm{Rh}\left(\mathrm{N}_{3}\right)\right]\right)$ and the Active [(Allyl-Ene $) \mathbf{R h}^{\mathrm{III}}$ $\mathrm{OH}]^{+}$Species II

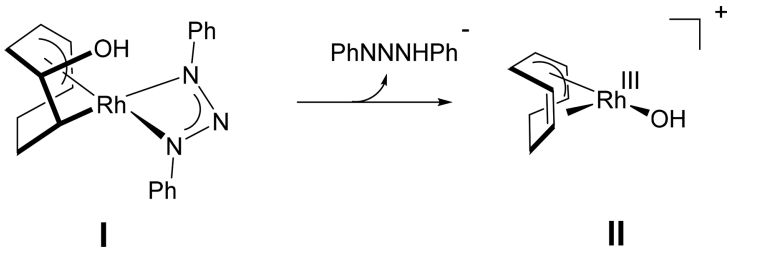

effect of the stereoregularity (syndiotactic instead of atactic) of these type of polymers on their LCST behavior. We have previously shown that the active species in the $\mathrm{Rh}$-catalyzed polymerization of diazoacetates is the $\left[\left(\mathrm{C}_{8} \mathrm{H}_{11}\right) \mathrm{Rh}^{\mathrm{III}}-\mathrm{OH}\right]^{+}$ species II, formed in situ from precatalyst I. This active species II gives the highest stereocontrol as well as the highest initiation efficiency known in the polymerization of diazoacetates. $^{41}$

Herein we describe the Rh-catalyzed polymerization of silylprotected diazoacetates, using complex I, and subsequent deprotection of these functionalized polymers to yield the desired polymers, functionalized with a hydroxyl-containing side chain at every carbon atom of the polymer backbone. On the basis of our previous results, ${ }^{41}$ we expected that polymers with a stereoregular and dense packing of hydroxyl groups in the polymer chain would be obtained. We show that indeed syndiotactic polymers are formed and that their tacticity and the length and the type of side chains affect the behavior of these polymers in aqueous media. Those polymers with the proper hydrophilic/hydrophobic balance show thermoresponsive behavior in aqueous solution. The influence of the tacticity, $M_{\mathrm{w}}$ (controlled by alcohol-mediated chain transfer ${ }^{40}$ ), and the concentration of the polymer solutions on their thermoresponsive behavior is demonstrated.

\section{RESULTS AND DISCUSSION}

Rh-Catalyzed Synthesis of Hydroxy-Containing Polymers from Diazoacetates. The silyl-protected monomers ${ }^{s} \mathbf{M}_{x}$ with different spacer lengths $(x=2-5)$ were synthesized following a protocol similar to that reported by Ihara and coworkers. ${ }^{43}$ To synthesize the highly functionalized and stereoregular polymers, we used the allyl- $\beta$-alkyl hydroxide $\mathrm{Rh}$ catalyst precursor I (Scheme 1$)$ instead of the $\left[\left(\eta^{3}\right.\right.$ $\left.\mathrm{C}_{3} \mathrm{H}_{5}\right) \mathrm{PdCl}$ catalyst used by Ihara and co-workers. ${ }^{43}$ Subsequent deprotection of polymers $\mathbf{p}^{\mathrm{s}} \mathbf{M}_{x}(x=2-5)$ with $\mathrm{HCl}$ in a THF/MeOH mixture produced the hydroxycontaining polymers $\mathbf{p} \mathbf{M}_{x}(x=2-5)$ in high yields (Scheme 2 ).

The polymerization of the silyl-protected monomers was performed in $\mathrm{CH}_{2} \mathrm{Cl}_{2}$ with a monomer/catalyst ratio of 50:1. To this solution the monomer was added at $0{ }^{\circ} \mathrm{C}$, after which the reaction mixture was allowed to warm up to room temperature and stirred over a period of $16 \mathrm{~h}$. The thus formed polymers were isolated and separated from co-produced oligomers by precipitation with methanol. The results of the polymerization reactions are summarized in Table 1 .

In entry 3, polymerization of ${ }^{\mathrm{s}} \mathbf{M}_{3}$ was performed using $\left[\left(\eta^{3}\right.\right.$ $\left.\left.\mathrm{C}_{3} \mathrm{H}_{5}\right) \mathrm{PdCl}\right]$ as catalyst, also used by Ihara and co-workers, ${ }^{43}$ to compare the $\mathrm{Pd}$ and $\mathrm{Rh}$ complexes as catalysts in the polymerization of these diazoacetates. The use of $\left[\left(\eta^{3}-\right.\right.$ $\left.\mathrm{C}_{3} \mathrm{H}_{5}\right) \mathrm{PdCl}$ causes a decrease of both yield and $M_{\mathrm{w}}$ but produces polymers with a narrower polydispersity than rhodium catalyst I (see Table 1, entries 2 and 3 ).

By changing the monomer/catalyst ratio to 25:1 (Table 1 , entry 6), we were able to synthesize polymers with a molecular weight almost half of the $M_{w}$ obtained when using a 50:1 ratio (Table 1, entry 5). Our group ${ }^{40}$ and the group of Ihara ${ }^{26}$ have independently reported that in the presence of alcohols or water Rh- and Pd-catalyzed polymerization of diazoacetates proceeds to give polymers. Ihara showed that when using $\left[\left(\eta^{3}-\right.\right.$ $\left.\mathrm{C}_{3} \mathrm{H}_{5}\right) \mathrm{PdCl}$ as the catalyst, direct polymerization of the unprotected hydroxyl-containing diazoacetate $\mathbf{M}_{5}$ is possible and forms the same polymers as when using the protected monomer ${ }^{s} \mathbf{M}_{5} \cdot{ }^{43}$ Therefore, to avoid time-consuming protection-deprotection processes, we attempted to polymerize the unprotected monomer $\mathbf{M}_{5}$ with precatalyst $\mathbf{I}$, but unfortunately only dimers were formed in this case. So this approach was discarded.

As alcohols are known to act as chain-transfer agents in Rhmediated carbene polymerization, ${ }^{40}$ we investigated the effect of alcohol on the polymerization of the silyl-protected monomer ${ }^{s} \mathbf{M}_{5}$ to control the chain length of the resulting polymer $\mathbf{p}^{\mathrm{s}} \mathbf{M}_{5}$. As such, monomer ${ }^{\mathrm{s}} \mathbf{M}_{5}$ was polymerized in the presence of different amounts of methanol (Table 1, entries 79). As expected, increasing the amount of methanol led to

Scheme 2. Synthesis of the Silyl-Protected Diazoacetates ${ }^{\mathrm{s}} \mathbf{M}_{x}$, Followed by Polymerization with the Rh Catalyst Precursor I and Subsequent Deprotection to Obtain Hydroxyl-Containing Polymers $\mathrm{pM}_{x}(x=2-5)$
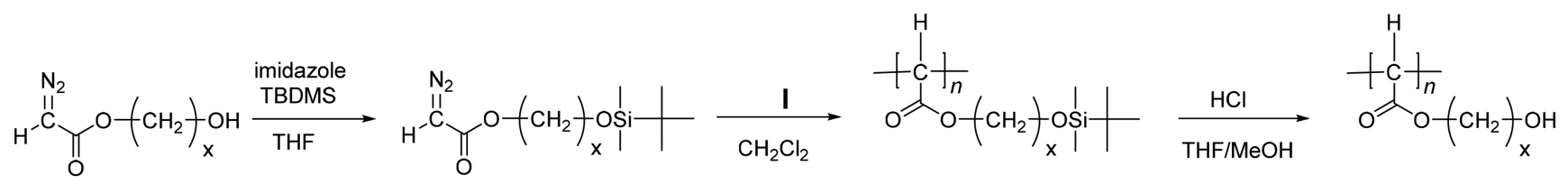

$$
\begin{gathered}
M_{\mathbf{x}} \\
x=2-5
\end{gathered}
$$$$
{ }^{s} \mathbf{M}_{\mathbf{x}}
$$$$
\mathbf{p}^{\mathbf{s}} \mathbf{M}_{\mathbf{x}}
$$$$
\mathrm{pM}_{\mathbf{x}}
$$ 
Table 1. Polymerization Results Using Monomers ${ }^{\mathrm{s}} \mathbf{M}_{2}-{ }^{\mathrm{s}} \mathbf{M}_{5}{ }^{a}$

\begin{tabular}{|c|c|c|c|c|c|c|c|}
\hline entry & monomer & solvent $\left(\mathrm{CH}_{2} \mathrm{Cl}_{2}: \mathrm{MeOH}\right)$ & catalyst & yield (\%) & $M_{\mathrm{w}}(\mathrm{kDa})$ & $M_{\mathrm{n}}(\mathrm{kDa})$ & $M_{\mathrm{w}} / M_{\mathrm{n}}$ \\
\hline 1 & ${ }^{\mathrm{s}} \mathbf{M}_{2}$ & $1: 0$ & I & 47 & 14 & 9.9 & 1.4 \\
\hline 2 & ${ }^{\mathrm{s}} \mathbf{M}_{3}$ & $1: 0$ & I & 52 & 28 & 16 & 1.7 \\
\hline 3 & ${ }^{\mathrm{s}} \mathbf{M}_{3}$ & $1: 0$ & $\left(\eta^{3}-\mathrm{C}_{3} \mathrm{H}_{5}\right) \mathrm{PdCl}$ & 33 & 0.63 & 0.62 & 1.0 \\
\hline 4 & ${ }^{\mathrm{s}} \mathbf{M}_{4}$ & $1: 0$ & I & 64 & 29 & 13 & 2.2 \\
\hline 5 & ${ }^{s} \mathbf{M}_{5}$ & $1: 0$ & $\mathbf{I}$ & 61 & 460 & 125 & 3.7 \\
\hline 6 & ${ }^{\mathrm{s}} \mathbf{M}_{5}$ & $1: 0$ & $\mathbf{I}^{b}$ & 54 & 263 & 64 & 4.1 \\
\hline 7 & ${ }^{s} \mathbf{M}_{5}$ & $4: 1$ & I & 49 & 155 & 70 & 2.2 \\
\hline 8 & ${ }^{\mathrm{s}} \mathbf{M}_{5}$ & $1: 1.5$ & I & 55 & 121 & 40 & 3.0 \\
\hline 9 & ${ }^{s} \mathbf{M}_{5}$ & $0: 1$ & I & 24 & 18 & 12 & 1.6 \\
\hline
\end{tabular}

${ }^{a}$ Reaction conditions: monomer/ $[\mathrm{Rh}]=50: 1$; solvent $\mathrm{CH}_{2} \mathrm{Cl}_{2}$ or a mixture of $\mathrm{CH}_{2} \mathrm{Cl}_{2}$ and $\mathrm{MeOH}$; addition of monomer at $0{ }^{\circ} \mathrm{C}$ followed by warming up to room temperature and stirring for $16 \mathrm{~h} .{ }^{b}$ Monomer $/[\mathrm{Rh}]=25: 1$.
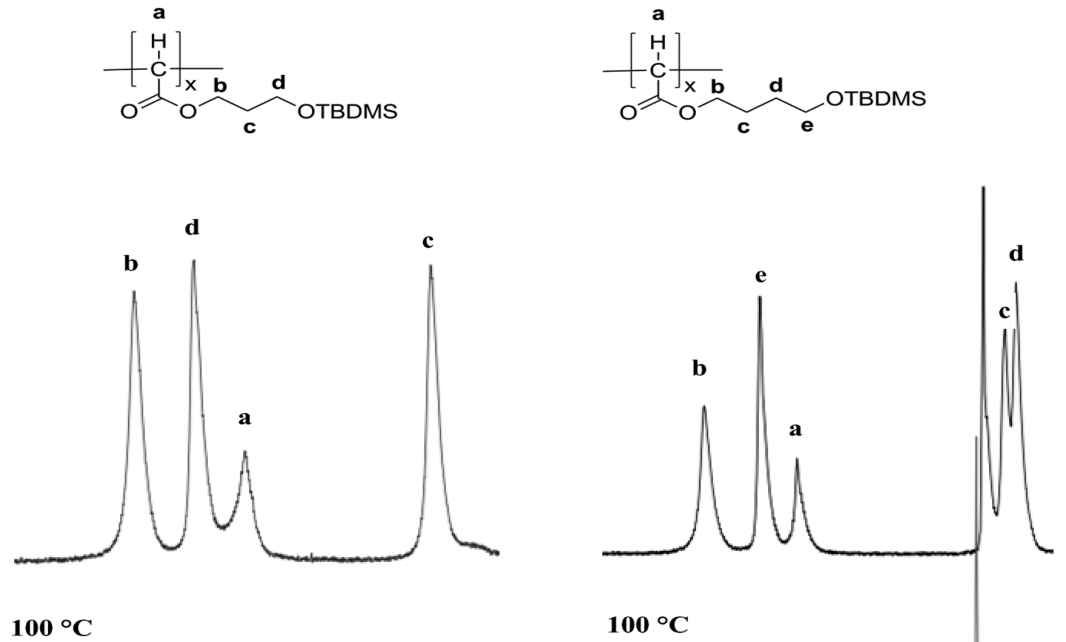

$100{ }^{\circ} \mathrm{C}$

$100{ }^{\circ} \mathrm{C}$
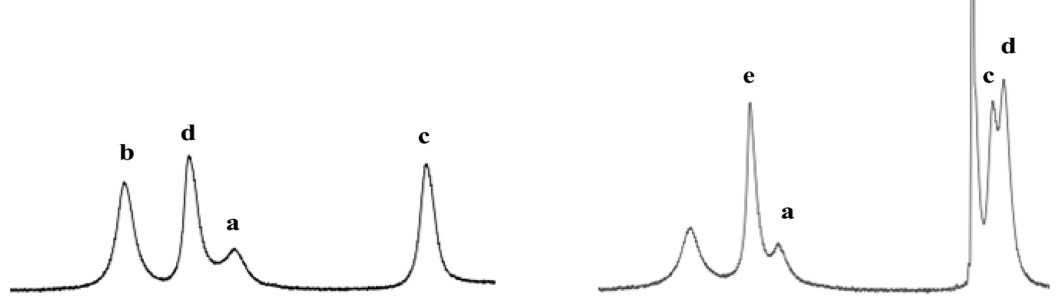

$20^{\circ} \mathrm{C}$

$20^{\circ} \mathbf{C}$
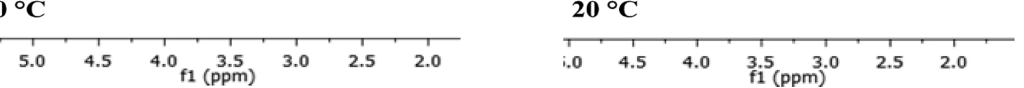

Figure 1. Variable temperature ${ }^{1} \mathrm{H}$ NMR experiment of $\mathbf{p}^{\mathrm{s}} \mathbf{M}_{3}$ and $\mathbf{p}^{\mathrm{s}} \mathbf{M}_{4}$ in benzene- $d_{6}$ and toluene- $d_{8}$, respectively.
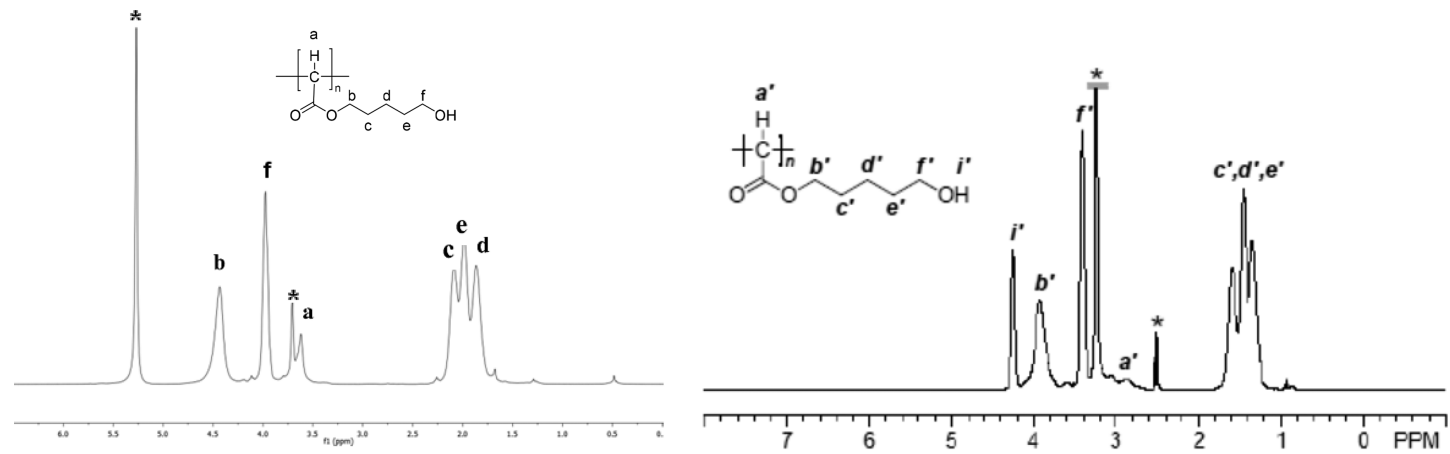

Figure 2. ${ }^{1} \mathrm{H}$ NMR spectrum (methanol- $d_{4}$ ) of $\mathbf{p M}_{5}$ obtained by polymerization of ${ }^{\mathbf{s}} \mathbf{M}_{5}$ catalyzed by Rh-catalyst $\mathbf{I}$ (left) and ${ }^{1} \mathrm{H}$ NMR spectrum taken from Ihara and co-workers ${ }^{43}$ (DMSO- $d_{6}$ ) of polyS5' formed by polymerization of $\mathbf{S} 5$ with $\left[\left(\eta^{3}-\mathrm{C}_{3} \mathrm{H}_{5}\right) \mathrm{PdCl}\right]$ (right). Signals marked with an asterisk correspond to the solvent and traces of water. 


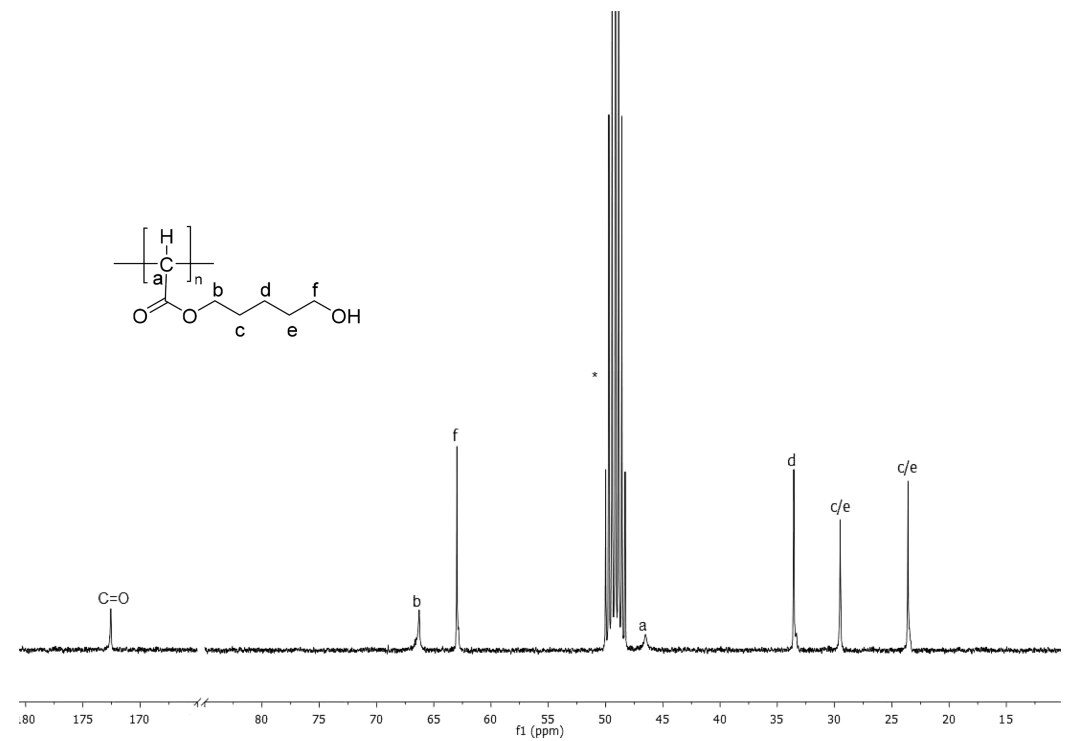

Figure $3 .{ }^{13} \mathrm{C}$ NMR spectrum (methanol- $d_{4}$ ) of $\mathbf{p M}_{5}$. Signals marked with an asterisk correspond to the solvent.

Table 2. Solubility Studies of Polymer $\mathrm{pM}_{5}$ in Aqueous Solution ${ }^{a}$

\begin{tabular}{|c|c|c|c|c|c|c|c|c|c|}
\hline \multicolumn{7}{|c|}{$\mathbf{p}^{\mathrm{s}} \mathbf{M}_{5}$} & \multicolumn{3}{|c|}{$\mathbf{p}^{\mathrm{s}} \mathbf{M}_{5}{ }^{a}$} \\
\hline entry & solvent & yield (\%) & $M_{\mathrm{w}}(\mathrm{kDa})$ & $M_{\mathrm{n}}(\mathrm{kDa})$ & $M_{\mathrm{w}} / M_{\mathrm{n}}$ & yield $\mathbf{p M}_{5}(\%)$ & entry & {$\left[\mathbf{p M}_{5}\right](\mathrm{wt} \%)$} & $\operatorname{LCST}\left({ }^{\circ} \mathrm{C}\right)$ \\
\hline \multirow{6}{*}{1} & \multirow{6}{*}{$1: 0$} & \multirow{6}{*}{61} & \multirow{6}{*}{460} & \multirow{6}{*}{125} & \multirow{6}{*}{3.7} & \multirow{6}{*}{$\sim 100$} & 1a & 0.50 & 6.6 \\
\hline & & & & & & & $1 \mathrm{~b}$ & $0.26^{b}$ & 8.5 \\
\hline & & & & & & & $1 \mathrm{c}$ & 0.10 & 9.6 \\
\hline & & & & & & & $1 \mathrm{~d}$ & $0.07^{b}$ & 13.7 \\
\hline & & & & & & & le & 0.05 & 15.8 \\
\hline & & & & & & & 1f & $0.03^{b}$ & 17.5 \\
\hline \multirow{3}{*}{2} & \multirow{3}{*}{$4: 1$} & \multirow{3}{*}{49} & \multirow{3}{*}{155} & \multirow{3}{*}{70} & \multirow{3}{*}{2.2} & \multirow{3}{*}{$\sim 100$} & $2 \mathrm{a}$ & 0.50 & 7.8 \\
\hline & & & & & & & $2 b$ & 0.10 & 10.5 \\
\hline & & & & & & & $2 \mathrm{c}$ & 0.05 & 12.9 \\
\hline \multirow{3}{*}{3} & \multirow{3}{*}{$1: 1.5$} & \multirow{3}{*}{55} & \multirow{3}{*}{121} & \multirow{3}{*}{40} & \multirow{3}{*}{3} & \multirow{3}{*}{92} & $3 a$ & 0.50 & 7.6 \\
\hline & & & & & & & $3 b$ & 0.10 & 9.8 \\
\hline & & & & & & & $3 c$ & 0.05 & 11.5 \\
\hline \multirow{3}{*}{4} & \multirow{3}{*}{$0: 1$} & \multirow{3}{*}{24} & \multirow{3}{*}{18} & \multirow{3}{*}{12} & \multirow{3}{*}{1.6} & \multirow{3}{*}{86} & $4 a$ & 0.50 & 7.2 \\
\hline & & & & & & & $4 \mathrm{~b}$ & 0.10 & 17.3 \\
\hline & & & & & & & $4 c$ & 0.05 & 25.3 \\
\hline
\end{tabular}

${ }^{a}$ Aqueous solutions of $\mathbf{p} \mathbf{M}_{\mathbf{5}}$ were prepared by adding demineralized water to the polymers. At room temperature $\mathbf{p} \mathbf{M}_{\mathbf{5}}$ is insoluble in water, but upon cooling to $4{ }^{\circ} \mathrm{C}$ most of the polymer dissolved. A small part of the polymer formed a swollen gel-like material, which largely dissolved upon sonication of the mixture in a $4{ }^{\circ} \mathrm{C}$ room. Separating the solution from the gel and warming the solution to room temperature produced an opaque aggregate. ${ }^{b}$ Concentrations of these solutions were determined after the UV-vis measurements by freeze-drying the aqueous solutions and weighing the polymer residue.

shorter polymers without affecting the polymer yield much, even up to a $\mathrm{CH}_{2} \mathrm{Cl}_{2}: \mathrm{MeOH}$ ratio of $1: 1.5$ (Table 1, entries 7 and 8). A huge decrease of $M_{\mathrm{w}}$ and $M_{\mathrm{n}}$ was observed when polymerization was attempted in $100 \% \mathrm{MeOH}$, but in this case also the yield is compromised (Table 1, entry 9). This is most likely caused by increased formation of (very) short oligomers, which remain soluble in the methanol solvent, which was used to wash and separate the polymer fraction from the oligomer and dimer fractions. Nonetheless, the $M_{\mathrm{w}}$ and $M_{\mathrm{n}}$ of the polymers can be tuned, both by varying the monomer/catalyst feed ratio and by the addition of varying amounts of $\mathrm{MeOH}$ to the reaction mixture.

The hydroxy-containing polymers $\mathbf{p} \mathbf{M}_{x}(x=2-5)$ required for solubility studies in water were obtained in high yields by deprotection of the corresponding silyl-protected polymers $\mathbf{p}^{\mathrm{s}} \mathbf{M}_{x}(x=2-5)$, using $\mathrm{HCl}$ in a $\mathrm{THF} / \mathrm{MeOH}$ mixture (Scheme 2).

To investigate the stereoregularity of the polymers formed by $\mathrm{Rh}$ catalyst I, we characterized the polymers by NMR. First, a variable temperature ${ }^{1} \mathrm{H}$ NMR experiment with $\mathbf{p}^{s} \mathbf{M}_{3}$ and $\mathbf{p}^{\mathrm{s}} \mathbf{M}_{4}$ formed by Rh catalyst $\mathbf{I}$ showed a sharpening of all ${ }^{1} \mathrm{H}$ NMR peaks upon heating to $100{ }^{\circ} \mathrm{C}$ (Figure 1), which confirms the expected highly syndiotactic nature of $\mathbf{p}^{\mathbf{s}} \mathbf{M}_{3}$ and $\mathbf{p}^{\mathrm{s}} \mathbf{M}_{4}$. Second, comparison of the ${ }^{1} \mathrm{H}$ NMR spectra of deprotected syndiotactic $\mathbf{p M}_{5}$ prepared by using complex I and atactic $\mathbf{p} \mathbf{M}_{5}$ prepared by Ihara and co-workers using $\left[\left(\eta^{3}\right.\right.$ $\left.\left.\mathrm{C}_{3} \mathrm{H}_{5}\right) \mathrm{PdCl}\right]^{43}$ showed that the signal for the polymer backbone (peak a in Figure 2) is considerably sharper for syndiotactic $\mathbf{p M}_{5}$, indicative for the formation of highly syndiotactic polymers using $\mathrm{Rh}$ complex $\mathbf{I})^{36}$ while $\left[\left(\eta^{3}-\right.\right.$ $\left.\left.\mathrm{C}_{3} \mathrm{H}_{5}\right) \mathrm{PdCl}\right]$ produces essentially atactic polymers. ${ }^{29-32,42,43}$ 
Third, the sharp signals in the ${ }^{13} \mathrm{C}$ NMR spectrum of $\mathbf{p} \mathbf{M}_{5}$ and the resemblance to the NMR signature of our previously reported syndiotactic polymers unequivocally show that a syndiotactic polymer is formed by catalyst I (Figure 3).

Solubility Studies of the Hydroxyl-Containing Polymer $\mathrm{pM}_{5}$ in Aqueous Media. It is known that hydroxylcontaining polymers with an appropriate hydrophilic/hydrophobic balance can undergo a temperature-dependent phase separation in aqueous solution. ${ }^{14-19,42,43}$

The critical solution temperature (CST) at which phase transition occurs depends among others on the ratio of hydrophilic and hydrophobic moieties in the polymer side chains. For instance, Ihara and co-workers recently showed that atactic $\mathbf{p M}_{5}$ (Scheme 2) show a lower critical solution temperature (LCST)-type phase separation in aqueous solutions, whereas polymers with shorter side chain spacers $(x=2-4)$ and thus less hydrophobic units in the side chain spacer show no thermoresponsivity. ${ }^{43}$ When the temperature of aqueous solutions of the thermoresponsive polymer $(x=5)$ increases above the LCST, the solutions become cloudy, indicating that insoluble aggregates are formed. Parameters that might be of influence on the thermoresponsive phase separation behavior of a polymer are its tacticity, molecular weight, and concentration. We were particularly curious to see whether there would be any influence of the tacticity of the produced polycarbenes on their critical solution temperature. Therefore, we investigated the thermoresponsive behavior of syndiotactic polymer $\mathbf{p M}_{5}$ in aqueous solution in comparison to the thermoresponsive behavior of its atactic analogue. The results are summarized in Table 2.

The aqueous $\mathbf{p M}_{5}$ solutions were examined with UV-vis spectroscopy to determine the LCST for these polymer solutions (Table 2, Figures 4 and 5). The LCST for these polymers is defined as the temperature at which the transmittance of $700 \mathrm{~nm}$ light is reduced by $50 \%$.

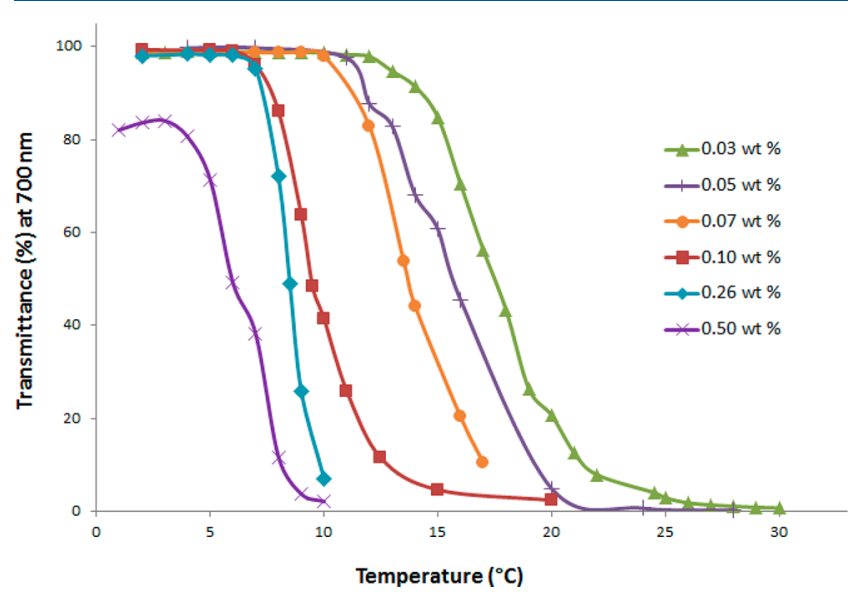

Figure 4. Temperature dependence of the transmittance at $700 \mathrm{~nm}$ (heating curves) for aqueous solutions of $\mathbf{p M}_{5}$. Influence of the concentration of $\mathbf{p M}_{5}\left(M_{\mathrm{w}} 460 \mathrm{kDa} ; M_{\mathrm{n}} 125 \mathrm{kDa}\right)$ on the LCST.

Measurement of the transmittance through aqueous solutions of syndiotactic $\mathbf{p M}_{5}\left(M_{\mathrm{w}} 460 \mathrm{kDa} ; M_{\mathrm{n}} 125 \mathrm{kDa}\right)$ of different concentrations $(0.03-0.5$ wt \%) showed that the LCST of the syndiotactic polymer increases with decreasing concentration (Figure 4 and Table 2, entries 1a-1f).

To investigate how the polymer tacticity influences the LCST, we compared atactic $\mathbf{p} \mathbf{M}_{5}$ reported by Ihara ${ }^{43}$ ( 0.5 wt $\%$

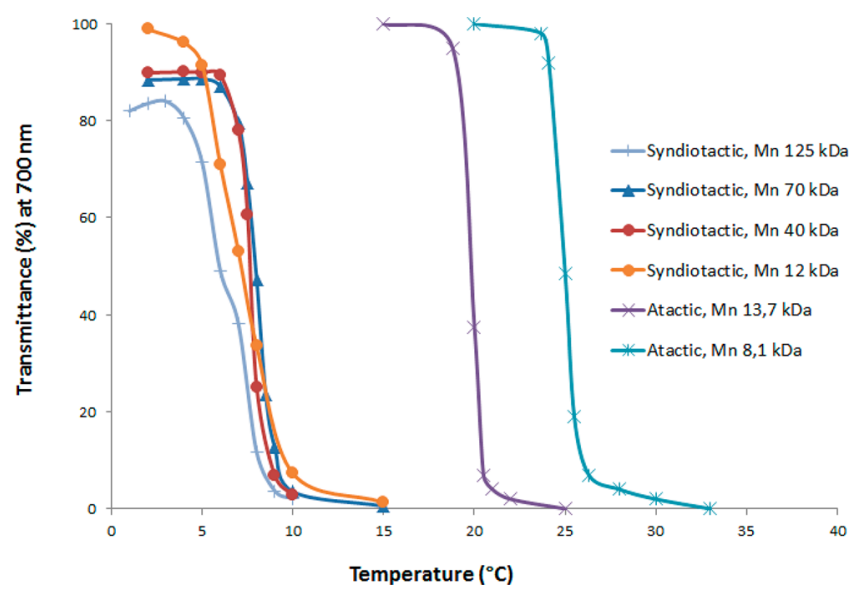

Figure 5. Temperature dependence of the transmittance at $700 \mathrm{~nm}$ (heating curves) for 0.5 wt $\%$ aqueous solutions of $\mathbf{p M}_{5}$. Influence of the $M_{n}$ on the LCST and comparison to the atactic analogue of $\mathbf{p} \mathbf{M}_{5}$. Curves from the atactic polymers are taken from ref 43 .

in aqueous solution. $M_{\mathrm{n}}=13.7 \mathrm{kDa}, M_{\mathrm{w}} / M_{\mathrm{n}}=1.66$, LCST = $20{ }^{\circ} \mathrm{C}$ ) with one of our syndiotactic $\mathbf{p M}_{5}$ samples of roughly the same molecular weight and PDI and the same concentration in aqueous solution (Table 2, entry $4 \mathrm{a} ; M_{\mathrm{n}}=$ $12 \mathrm{kDa}, M_{\mathrm{w}} / M_{\mathrm{n}}=1.60$, LCST $=7.2{ }^{\circ} \mathrm{C}$ ). In this direct comparison, the tacticity of the polymer proved to have a large influence on the thermoresponsive behavior of the polymers. There is a difference of $\sim 13{ }^{\circ} \mathrm{C}$ between the LCST of the atactic and syndiotactic polymers, with the syndiotactic polymers consistently having lower LCST values than the atactic polymers (Figure 5). Similar differences have been observed for aqueous solutions of poly $(N$-isopropylacrylamide) polymers with different tacticities, where a higher percentage of meso diad content also resulted in a lower LCST. $44-46$

The lower LCST of syndiotactic $\mathbf{p} \mathbf{M}_{5}$ compared to its atactic analogue can perhaps be explained by a different type of aggregates formed by the syndiotactic polymers. Thermotropic and lyotropic LC behavior of these type of polymers was demonstrated (DSC, POM, X-ray diffraction, SAXS, WAXS, and solid-state NMR), and scanning tunneling microscopy (STM) revealed that syndiotactic poly(ethylidene acetate) (PEA) self-assembles into triple helices (Figure 6, top). ${ }^{47}$ Subsequent studies by Tokita, Shikinaka, Ihara, and co-workers confirmed that PEA and related syndiotactic polymers of diazoacetates show thermotropic liquid crystalline behavior due to a rod-like helical conformation in the polymer backbone. $^{48-50}$ The syndiotactic polymer $\mathbf{p M}_{\mathbf{5}}$ is likely to form similar triple helices, and the forces keeping the aggregates together are likely to be stronger in such triplehelix aggregates than in the atactic material, leading to a lower LCST for the syndiotactic polymer than for the atactic material (Figure 6, bottom). Solvation into individual polymer chains in solution is enthalpy-driven, while formation of aggregates at higher temperature is an entropy-driven process, releasing water solvent molecules upon aggregation of the individual solvated polymer chains. The syndiotactic $\mathbf{p} \mathbf{M}_{5}$ polymers most likely form more densely packed aggregates than their atactic analogues, as they prefer to aggregate first into tightly packed triple helices before aggregating/crystallizing further. As a result, entropy effects are stronger for syndiotactic $\mathbf{p M}_{5}$ than 


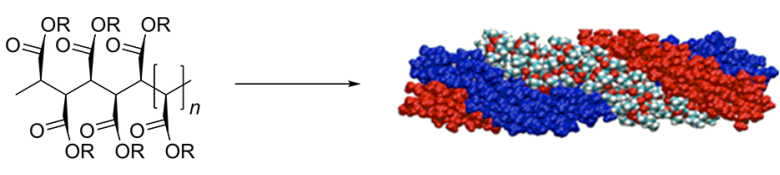

Syndiotactic $\mathbf{p} \mathbf{M}_{5}$

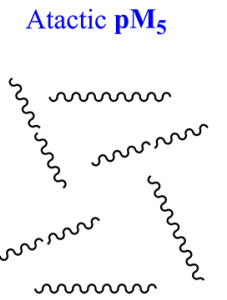

water-solvated polymer chains (enthalpy prevails)

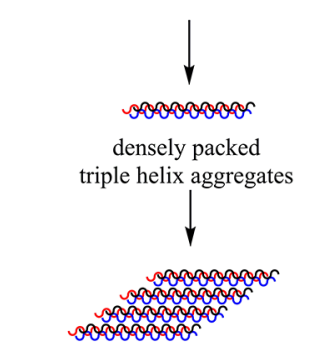

Further aggregation/crystallization to densely packed aggregates: Entropy prevails already at lower $T$

Figure 6. Top: structure of syndiotactic poly(ethylidene acetate) (left) and its aggregation into a triple helix (right). Bottom: proposed aggregation of syndiotactic $\mathbf{p} \mathbf{M}_{5}$ in water occurring at lower temperature than aggregation of its atactic analogue due to formation of more densely packed aggregates, thus releasing more water molecules involved in solvation of individual polymer chains upon aggregate formation, leading to larger entropy contributions.

for atactic $\mathbf{p} \mathbf{M}_{5}$, so that aggregation takes place already at a lower temperature (lower LCST).

The LCST values of the syndiotactic $\mathbf{p M}_{5}$ polymers with various molecular weights measured at $0.5 \mathrm{wt} \%$ concentrations are remarkably similar. The $12-70 \mathrm{kDa}$ samples seem to indicate a slight decrease in LCST with decreasing molecular weight (Table 2, entries $2 a, 3 a$, and $4 a$ ), but the differences in LCST are very small and the highest molecular weight (125 $\mathrm{kDa}$ ) sample breaks this trend (Table 2, entry 1a). This behavior contrasts with most other polymer solutions showing LCST-type phase separation behavior, as it is common for the LCST to clearly decrease with increasing molecular weight. The results are also in contrast with those obtained for the earlier reported atactic analogue of $\mathbf{p} \mathbf{M}_{5}$ for which the LCST also clearly decreases with increasing molecular weight for samples measured at $0.5 \mathrm{wt} \%$ concentrations $\left(M_{\mathrm{n}}=13.7 \mathrm{kDa}\right.$, LCST $=20{ }^{\circ} \mathrm{C}$ and $M_{\mathrm{n}}=8.1 \mathrm{kDa}, \mathrm{LCST}=25^{\circ} \mathrm{C}$, see Figure 5). The behavior observed for atactic $\mathbf{p M}_{5}$ (in contrast to syndiotactic $\mathbf{p} \mathbf{M}_{5}$ ) is the expected behavior and can attributed to increased entropy of mixing with decreasing $M_{\mathrm{n}}{ }^{13,42,43}$

Because the variations in the LCST at 0.5 wt \% concentrations are only very small and rather irregular despite large changes in $M_{n}$, we suspected that the concentrations of the syndiotactic $\mathbf{p M}_{5}$ polymers measured at $0.5 \mathrm{wt} \%$ were actually too high because of possible "saturation effects" in the LCST behavior. Similar "saturation" of the LCST values over wide concentration ranges has been observed also for other polymers. ${ }^{51-53}$ Within such saturation domains, the measured LCST values typically lie too close (i.e. within the margin of error) to draw any reliable conclusions. Indeed, also for syndiotactic $\mathbf{p} \mathbf{M}_{5}$ this proved to be the case. When the LCST is plotted as a function of both concentration and molecular weight (Figure 7), it becomes clear that the LCST values of the

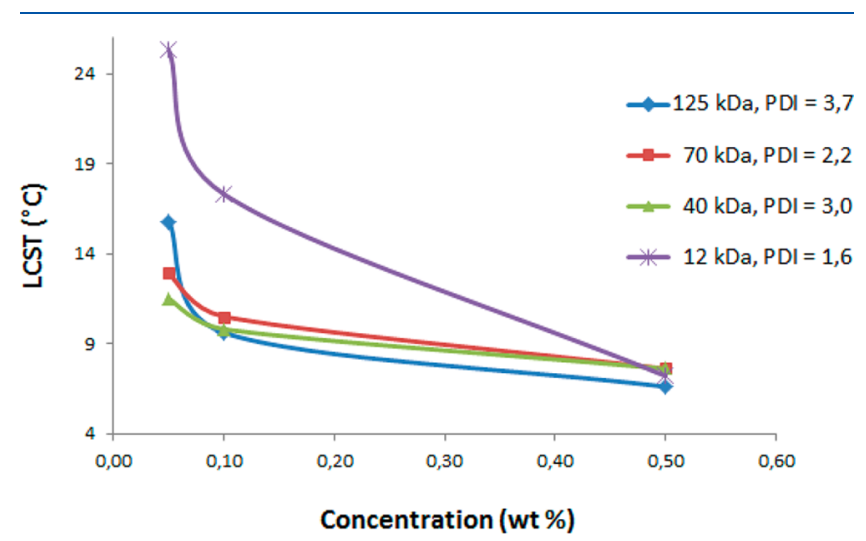

Figure 7. LCST as a function of concentration and $M_{\mathrm{n}}$.

three higher molecular weight polymers $(40,70$, and $125 \mathrm{kDa})$ levels off at concentrations higher than $0.1 \mathrm{wt} \%$. Above a concentration of $0.1 \mathrm{wt} \%$, the LCST values of the three polymers become more or less equal, independent of the molecular weight and PDI and become only slightly lower upon increasing the concentration further. The onset of this "saturation effect" seems to occur the earliest for the highest molecular weight polymer $(125 \mathrm{kDa})$.

Interestingly, at much lower concentrations (0.05 wt \%), the higher molecular weight polymers $(40-125 \mathrm{kDa})$ clearly show an "abnormal" LCST behavior, in which the LCST increases as molecular weight increases. For the higher $M_{n}$ polymers (40$125 \mathrm{kDa}$ ), this behavior seems unaffected by differences in the PDI (for lower weight polymers measured at low concentrations there may be an influence). ${ }^{51,52,54-56}$ Similar "abnormal" dependence of the LCST on $M_{\mathrm{n}}$ was also found in aqueous solutions of poly $(N$-isopropylacrylamide $)$ by Tong and co-workers. ${ }^{51,57}$

As described above, for the shorter (less entangled) polymer chains, association into triple helix preaggregates is probably easier than for the longer (more entangled) ones, thus explaining the observed "abnormal dependence" of the LCST on the molecular weight of $\mathbf{p M}_{5}$ (Figure 6).

However, below a critical molecular weight this behavior may deviate, since we found that the lowest molecular weight polymer $(12 \mathrm{kDa})$ behaves completely different from the higher molecular weight polymers $(40-125 \mathrm{kDa})$ (Figure 7). For this short polymer, the LCST "saturation effect" starts at much higher concentrations and proceeds with a much steeper slope. Furthermore, the LCST of this polymer is considerably higher than that of the other polymers at $0.05 \mathrm{wt} \%$ concentration and clearly does not follow the same "abnormal" LCST behavior as was observed for the higher molecular weight polymers. This deviant behavior could originate from several causes. Perhaps the $12 \mathrm{kDa}$ polymer is too short to form the same aggregates as the higher molecular weight polymers (Figure 6). Alternatively, for this short polymer the Flory-Huggins interaction parameter may become dominant, ${ }^{52,53}$ thereby overruling the "abnormal" LCST behavior. A third possible cause for its normal LCST behavior may be the 
methoxy chain-end groups, which are introduced by using methanol as a chain-transfer agent to synthesize these short polymers. Lastly, we cannot exclude an influence of the polydispersity of the $12 \mathrm{kDa}$ polymer, which is narrower than the PDI values of the heavier polymers $(40-125 \mathrm{kDa})$.

The results described above and related studies with poly(ethylene glycol)s, ${ }^{42}$ poly-HEMA, ${ }^{16}$ poly(vinyl ether)s, ${ }^{17-19}$ and polyacrylamides ${ }^{45}$ have revealed that variation of the polymer backbone and/or side chains can cause significant changes in the phase separation behavior. This prompted us to also synthesize a syndiotactic polymer containing ethylene glycol side chains. See the Supporting Information for details. However, the thus obtained $-\left[\mathrm{CH}\left\{\mathrm{C}(=\mathrm{O})\left(\mathrm{CH}_{2}\right)_{2} \mathrm{O}\right.\right.$ $\left.\left.\left(\mathrm{CH}_{2}\right)_{2} \mathrm{OH}\right\}\right]_{x}-$ polymer turned out to be a rare example of a syndiotactic high- $M_{\mathrm{w}}$ polymer that is fully water-soluble. It does not undergo any phase separation over a temperature range between 0 and $70{ }^{\circ} \mathrm{C}$.

\section{CONCLUSIONS}

Overall, this study has clarified that Rh-catalyzed carbene polymerization enables the synthesis of thermoresponsive, syndiotactic, high molecular weight polymers. The molecular weight of these polymers can be tuned by changing the monomer/catalyst ratio or by using methanol-mediated chain transfer. Polymer $\mathbf{p M}_{5}$ was found to have an appropriate hydrophilic/hydrophobic balance to undergo a temperaturedependent phase separation in aqueous solution. The LCST of $\mathbf{p M}_{5}$ was demonstrated to be drastically influenced by tacticity; the LCST of syndiotactic $\mathbf{p M}_{5}$ is much lower than that of its atactic analogue with the same molecular weight, and in contrast to atactic $\mathbf{p} \mathbf{M}_{5}$, syndiotactic $\mathbf{p} \mathbf{M}_{5}$ reveals an "abnormal dependence" of the LCST on the molecular weight of the polymer. By changing the molecular weight and the concentration of these polymers, we can fine-tune the LCST of an aqueous solution of $\mathbf{p} \mathbf{M}_{5}$. Modification of the polymer backbone and/or side chains can cause significant changes in the phase separation behavior of these polymers, providing future opportunities for designing novel thermoresponsive polymers for a broad scope of applications.

\section{EXPERIMENTAL SECTION}

General. The silyl-protected diazoacetates ${ }^{\mathrm{s}} \mathbf{M}_{x}$ were prepared according to the literature, ${ }^{43}$ except that for the synthesis of the monomers anhydrous solvents were used during the reaction and non-dried solvents during work-up. $N, N^{\prime}$-Ditosylhydrazine $(\mathrm{TsNH})_{2}$ necessary for the monomer synthesis was prepared according to the method published by Fukuyama and co-workers. ${ }^{58} \mathrm{Rh}$ precatalyst I was synthesized according to previously published methods. ${ }^{37,59}$ Further details can be found in the Supporting Information.

Polymerization of the Diazoacetates; Formation of Polymers $\mathbf{p}^{\mathrm{s}} \mathbf{M}_{\mathbf{2}}-\mathbf{P}^{\mathrm{s}} \mathbf{M}_{5}$. As an example, the synthesis of $\mathbf{p}^{\mathrm{s}} \mathbf{M}_{\mathbf{5}}$ is described. In a dry Schlenk flask equipped with a stir bar and septum, ${ }^{\mathrm{s}} \mathbf{M}_{5}(1.28$ $\mathrm{g}, 4.47 \mathrm{~mol}$ ) was dissolved in $5 \mathrm{~mL}$ of dry dichloromethane (DCM). In another dried Schlenk flask $38.6 \mathrm{mg}(0.09 \mathrm{mmol})$ of Rh catalyst I (monomer:catalyst ratio 50:1) was dissolved in $2 \mathrm{~mL}$ of dry DCM and cooled to $0{ }^{\circ} \mathrm{C}$. The solution of ${ }^{s} \mathbf{M}_{5}$ was added in a dropwise manner to the solution of Rh catalyst, using a syringe. Evolution of $\mathrm{N}_{2}$ was observed. After the addition of ${ }^{s} \mathbf{M}_{5}$, the reaction mixture was allowed to warm up to room temperature and stirred overnight. The reaction mixture was concentrated until a volume of ca. $1 \mathrm{~mL}$ was left, after which dry $\mathrm{MeOH}$ was added to precipitate the polymer. The polymer was separated from the supernatant by centrifugation and three washing steps with dry $\mathrm{MeOH}$. This yielded $\mathbf{p}^{\mathbf{s}} \mathbf{M}_{5}$ as an offwhite solid $(0.69 \mathrm{~g}, 59 \%) .{ }^{1} \mathrm{H}$ NMR $\left(\mathrm{CDCl}_{3}, 300.1 \mathrm{MHz}\right), \delta(\mathrm{ppm})$ : 3.95 (br, $\left.2 \mathrm{H},-\mathrm{OCH}_{2}-\right), 3.59$ (br, $\left.2 \mathrm{H}, \mathrm{CH}_{2} \mathrm{OSi}-\right)$, $3.13(\mathrm{br}, 1 \mathrm{H}$,
$\left.-[\mathrm{CH}]_{n}-\right), 1.62\left(\mathrm{br}, 2 \mathrm{H},-\mathrm{CH}_{2} \mathrm{CH}_{2} \mathrm{CH}_{2} \mathrm{CH}_{2} \mathrm{CH}_{2}-\right), 1.53($ br, $2 \mathrm{H}$, $\left.-\mathrm{CH}_{2} \mathrm{CH}_{2} \mathrm{CH}_{2} \mathrm{CH}_{2} \mathrm{CH}_{2}-\right), 1.36\left(\mathrm{br}, 2 \mathrm{H},-\mathrm{CH}_{2} \mathrm{CH}_{2}-\right.$ $\left.\mathrm{CH}_{2} \mathrm{CH}_{2} \mathrm{CH}_{2}-\right), 0.90\left(\mathrm{~s}, 9 \mathrm{H},-\mathrm{Si}{ }^{t} \mathrm{Bu}\right), 0.05\left(\mathrm{~s}, 6 \mathrm{H},-\mathrm{Si}\left(\mathrm{CH}_{3}\right)_{2}-\right)$.

$\mathbf{p}^{\mathrm{s}} \mathbf{M}_{2}$. Yield: $47 \%$. ${ }^{1} \mathrm{H}$ NMR $\left(\mathrm{CDCl}_{3}, 300.1 \mathrm{MHz}\right), \delta(\mathrm{ppm}): 4.25$ (br, $\left.2 \mathrm{H},-\mathrm{OCH}_{2}-\right), 3.69$ (br, $2 \mathrm{H},-\mathrm{CH}_{2} \mathrm{OSi}-, 3.39$ (br, $1 \mathrm{H}$, $\left.-[\mathrm{CH}]_{n}-\right), 0.93\left(\mathrm{~s}, 9 \mathrm{H},-\mathrm{Si} \mathrm{t}^{t} \mathrm{Bu}\right), 0.25\left(\mathrm{~s}, 6 \mathrm{H},-\mathrm{Si}\left(\mathrm{CH}_{3}\right)_{2}-\right)$.

$\mathbf{p}^{\mathrm{s}} \mathbf{M}_{3}$. Yield: $52 \% .{ }^{1} \mathrm{H}$ NMR $\left(\mathrm{CDCl}_{3}, 300.1 \mathrm{MHz}\right), \delta(\mathrm{ppm}): 4.11$ (br, $2 \mathrm{H},-\mathrm{OCH}_{2}-$ ), 3.71 (br, $2 \mathrm{H},-\mathrm{CH}_{2} \mathrm{OSi}-$ ), $3.12(\mathrm{br}, 1 \mathrm{H}$, $\left.-[\mathrm{CH}]_{n}-\right), 1.85\left(\mathrm{br}, 2 \mathrm{H},-\mathrm{CH}_{2} \mathrm{CH}_{2} \mathrm{CH}_{2}-\right), 0.93\left(\mathrm{~s}, 9 \mathrm{H},-\mathrm{Si}^{t} \mathrm{Bu}\right)$, $0.10\left(\mathrm{~s}, 6 \mathrm{H},-\mathrm{Si}\left(\mathrm{CH}_{3}\right)_{2}-\right)$.

$\mathbf{p}^{\mathrm{s}} \mathbf{M}_{4}$. Yield: $64 \%$. ${ }^{1} \mathrm{H}$ NMR $\left(\mathrm{CDCl}_{3}, 300.1 \mathrm{MHz}\right), \delta(\mathrm{ppm}): 4.01$ (br, $2 \mathrm{H},-\mathrm{OCH}_{2}-$ ), 3.65 (br, $2 \mathrm{H},-\mathrm{CH}_{2} \mathrm{OSi}-$ ), 3.15 (br, $1 \mathrm{H}$, $\left.-[\mathrm{CH}]_{n}-\right), 1.62\left(\mathrm{br}, 4 \mathrm{H},-\mathrm{CH}_{2} \mathrm{CH}_{2} \mathrm{CH}_{2} \mathrm{CH}_{2}-\right), 0.93(\mathrm{~s}, 9 \mathrm{H}$, $\left.-\mathrm{Si}{ }^{t} \mathrm{Bu}\right), 0.08$ (s, 6H, $\left.\mathrm{Si}\left(\mathrm{CH}_{3}\right)_{2}-\right)$.

Polymerization of ${ }^{s} \mathrm{M}_{5}$ via $\mathrm{MeOH}-$ Mediated Chain Transfer. The procedure followed is the same as for polymerization without chain transfer, except for the use of a solvent mixture of DCM and $\mathrm{MeOH}$ (total reaction volume between 5 and $7 \mathrm{~mL}$ ). Three chaintransfer polymerizations were performed with ${ }^{s} \mathbf{M}_{5}$, with DCM:MeOH ratios of $4: 1,1: 1.5$, and $0: 1$. The formed polymers $\left(\mathbf{p}^{\mathrm{s}} \mathbf{M}_{5}\right)$ were isolated according to the procedure described above.

Deprotection of the Silylated Polymers. Deprotection of the polymers was done with $\mathrm{HCl}$ in a $\mathrm{THF} / \mathrm{MeOH}$ mixture. After completion of the deprotection, all volatiles were evaporated, the crude solid was redissolved in as little as possible $\mathrm{MeOH}$, and the polymers were precipitated from the reaction mixture by addition of THF. The desilylated polymers were isolated in high yield (>90\%). The deprotection of $\mathbf{p}^{\mathrm{s}} \mathbf{M}_{5}$ is described as an example. In $5 \mathrm{~mL}$ of THF was dissolved $200 \mathrm{mg}(0.77 \mathrm{mmol})$ of $\mathbf{p}^{\mathbf{s}} \mathbf{M}_{5}$, and $\mathrm{MeOH}(1 \mathrm{~mL})$ was added to enhance the solubility of the formed desilylated polymer. Subsequently $1 \mathrm{~mL}$ of concentrated $\mathrm{HCl}(37 \%)$ was added in a dropwise manner. As soon as precipitation of solid was observed, a few extra drops of $\mathrm{MeOH}$ were added. After stirring for $1-2 \mathrm{~h}$ the solvents were evaporated on a rotavap until a volume of ca. $1 \mathrm{~mL}$ was left, and then more $\mathrm{MeOH}$ was added, after which solvents were again evaporated until a volume of ca. $1 \mathrm{~mL}$ was left. This step was repeated twice, after which the mixture was concentrated for the last time to ca. $0.5-1 \mathrm{~mL}$. Addition of THF $(\sim 10 \mathrm{~mL})$ resulted in precipitation of the deprotected polymer, which was collected using centrifugation. Washing with THF yielded $\mathbf{p} \mathbf{M}_{5}$ as an off-white sticky solid $(0.10 \mathrm{~g}$, 90\%). ${ }^{1} \mathrm{H}$ NMR (DMSO- $\left.d_{6}, 300.1 \mathrm{MHz}\right), \delta(\mathrm{ppm}): 4.40$ (b, $1 \mathrm{H}$, $\mathrm{OH}), 3.89$ (b, 2H, $\left.-\mathrm{OCH}_{2}-\right), 3.40\left(\mathrm{~b}, 2 \mathrm{H},-\mathrm{CH}_{2} \mathrm{OH}\right), 3.06(\mathrm{~b}, 1 \mathrm{H}$, $\left.-[\mathrm{CH}]_{n}-\right), 1.57\left(\mathrm{~b}, 2 \mathrm{H},-\mathrm{CH}_{2} \mathrm{CH}_{2} \mathrm{CH}_{2} \mathrm{CH}_{2} \mathrm{CH}_{2}-\right), 1.44(\mathrm{~b}, 2 \mathrm{H}$, $-\mathrm{CH}_{2} \mathrm{CH}_{2} \mathrm{CH}_{2} \mathrm{CH}_{2} \mathrm{CH}_{2}-$ ), 1.32 (b, $2 \mathrm{H},-\mathrm{CH}_{2} \mathrm{CH}_{2} \mathrm{CH}_{2} \mathrm{CH}_{2} \mathrm{CH}_{2}-$ ). ${ }^{13} \mathrm{C}$ NMR (methanol- $\left.d_{4}, 75.4 \mathrm{MHz}\right), \delta(\mathrm{ppm}): 172.6(\mathrm{C}=\mathrm{O}), 66.3$ $\left(\mathrm{OCH}_{2}\right), 63.0\left(\mathrm{CH}_{2} \mathrm{OH}\right), 46.5\left(-[\mathrm{CH}]_{n}-\right), 33.6\left(-\mathrm{CH}_{2} \mathrm{CH}_{2} \mathrm{CH}_{2}-\right.$ $\left.\mathrm{CH}_{2} \mathrm{CH}_{2}-\right), 29.5\left(-\mathrm{CH}_{2} \mathrm{CH}_{2} \mathrm{CH}_{2} \mathrm{CH}_{2} \mathrm{CH}_{2}-\right), 23.6\left(-\mathrm{CH}_{2} \mathrm{CH}_{2}-\right.$ $\mathrm{CH}_{2} \mathrm{CH}_{2} \mathrm{CH}_{2}-$ ).

\section{ASSOCIATED CONTENT}

\section{Supporting Information}

The Supporting Information is available free of charge on the ACS Publications website at DOI: 10.1021/acs.macromol.8b01150.

${ }^{1} \mathrm{H}$ and ${ }^{13} \mathrm{C}$ NMR spectra of $\mathbf{p M}_{5}$ and experimental procedures for all the monomers and polymers described in this paper $(\mathrm{PDF})$

\section{AUTHOR INFORMATION}

\section{Corresponding Author}

*E-mail: b.debruin@uva.nl (B.d.B.).

ORCID

Bas de Bruin: 0000-0002-3482-7669

Author Contributions

D.S.T. and M.L. contributed equally. 


\section{Notes}

The authors declare no competing financial interest.

\section{ACKNOWLEDGMENTS}

The work described in this paper was financially supported by The Netherlands Organization for Scientific Research (NWO TOP-Grant 716.015.001) and the Research Priority Area Sustainable Chemistry of the University of Amsterdam.

\section{REFERENCES}

(1) Gao, Y.; Wei, M.; Li, X.; Xu, W.; Ahiabu, A.; Perdiz, J.; Liu, Z.; Serpe, M. J. Stimuli-Responsive Polymers: Fundamental Considerations and Applications. Macromol. Res. 2017, 25, 513-527.

(2) Shravani, D.; Lakshmi, P. K. Preparation, Characterization and Potential Applications of Thermosensitive Polymers - a Review. Pharma Sci. Monit. 2011, 2, 48-71.

(3) Li, Z.; Guan, J. Thermosensitive Hydrogels for Drug Delivery. Expert Opin. Drug Delivery 2011, 8, 991-1007.

(4) Cheng, B.; Wei, M.-Y.; Liu, Y.; Pitta, H.; Xie, Z.; Hong, Y.; Nguyen, K. T.; Yuan, B. Development of Ultrasound-Switchable Fluorescence Imaging Contrast Agents Based on Thermosensitive Polymers and Nanoparticles. IEEE J. Sel. Top. Quantum Electron. 2014, 20, 67-80.

(5) Rzaev, Z. M. O.; Dinçer, S.; Pişkin, E. Functional Copolymers of $\mathrm{N}$-Isopropylacrylamide for Bioengineering Applications. Prog. Polym. Sci. 2007, 32, 534-595.

(6) Lemanowicz, M.; Gierczycki, A.; Kuźnik, W.; Milczyńska, J.; Bulanda, P. Application of Thermosensitive Polymers in Stabilization of Colloids. Adv. Powder Technol. 2016, 27, 471-480.

(7) Zhu, Y.; Xu, Y.; Huang, G. Synthesis and Aqueous Solution Properties of Novel Thermosensitive Polyacrylamide Derivatives. J. Appl. Polym. Sci. 2013, 130, 766-775.

(8) Bergbreiter, D. E.; Case, B. L.; Liu, Y.-S.; Caraway, J. W. Poly(NIsopropylacrylamide) Soluble Polymer Supports in Catalysis and Synthesis. Macromolecules 1998, 31, 6053-6062.

(9) Atkins, P.; de Paula, J. In Physical Chemistry, 7th ed.; Oxford University Press: New York, 2002; p 205.

(10) Schild, H. G. Poly ( $N$-isopropylacrylamide):Experiment, Theory and Application. Prog. Polym. Sci. 1992, 17, 163-249.

(11) de las Heras Alarcón, C.; Pennadam, S.; Alexander, C. Stimuli Responsive Polymers for Biomedical Applications. Chem. Soc. Rev. 2005, 34, 276-285.

(12) Liu, R.; Fraylich, M.; Saunders, B. R. Thermoresponsive Copolymers: From Fundamental Studies to Applications. Colloid Polym. Sci. 2009, 287, 627-643.

(13) Xia, Y.; Yin, X.; Burke, N. A. D.; Stöver, H. D. H. Thermal Response of Narrow-Disperse Poly(N-Isopropylacrylamide) Prepared by Atom Transfer Radical Polymerization. Macromolecules 2005, 38, 5937-5943.

(14) Vo, C.-D.; Rosselgong, J.; Armes, S. P.; Tirelli, N. StimulusResponsive Polymers Based on 2-Hydroxypropyl Acrylate Prepared by RAFT Polymerization. J. Polym. Sci., Part A: Polym. Chem. 2010, 48, 2032-2043.

(15) Eggenhuisen, T. M.; Becer, C. R.; Fijten, M. W. M.; Eckardt, R.; Hoogenboom, R.; Schubert, U. S. Libraries of Statistical Hydroxypropyl Acrylate Containing Copolymers with LCST Properties Prepared by NMP. Macromolecules 2008, 41, 5132-5140.

(16) Weaver, J. V. M; Bannister, I.; Robinson, K. L.; Bories-Azeau, X.; Armes, S. P.; Smallridge, M.; McKenna, P. Stimulus-Responsive Water-Soluble Polymers Based on 2-Hydroxyethyl Methacrylate. Macromolecules 2004, 37, 2395-2403.

(17) Shimomoto, H.; Kanaoka, S.; Aoshima, S. Precise Synthesis of End-Functionalized Thermosensitive Poly(vinylether)s by Living Cationic Polymerization. J. Polym. Sci., Part A: Polym. Chem. 2012, 50, 4137-4144.

(18) Sugihara, S.; Hashimoto, K.; Matsumoto, Y.; Kanaoka, S.; Aoshima, S. Thermosensitive Polyalcohols: Synthesis via Living
Cationic Polymerization of Vinyl Ethers with a Siloxy Group. J. Polym. Sci., Part A: Polym. Chem. 2003, 41, 3300-3312.

(19) Sugihara, S.; Kanaoka, S.; Aoshima, S. Thermosensitive Random Copolymers of Hydrophilic and Hydrophobic Monomers Obtained by Living Cationic Copolymerization. Macromolecules 2004, $37,1711-1719$.

(20) Note: e.g. atom transfer polymerization (ATRP), reversible addition fragmentation chain transfer polymerization (RAFT), and nitroxide-mediated polymerization (NMP).

(21) Boffa, L. S.; Novak, B. M. Copolymerization of Polar Monomers with Olefins Using Transition-Metal Complexes. Chem. Rev. 2000, 100, 1479-1493.

(22) Nakamura, A.; Ito, S.; Nozaki, K. Coordination-Insertion Copolymerization of Fundamental Polar Monomers. Chem. Rev. 2009, 109, 5215-5244.

(23) Jellema, E.; Jongerius, A. L.; Reek, J. N. H.; de Bruin, B. C1 Polymerisation and Related C-C Bond Forming "Carbene Insertion" Reactions. Chem. Soc. Rev. 2010, 39, 1706-1723.

(24) Xiao, L.; Li, Y.; Liao, L.; Liu, L. Denitrogen Alkene Polymerization of Bisdiazo Compounds by Copper(II) Catalysts. New J. Chem. 2013, 37, 1874-1877.

(25) Liu, L.; Song, Y.; Li, H. Carbene Polymerization: Characterization of Poly(carballyloxycarbene). Polym. Int. 2002, 51, 10471049.

(26) Ihara, E.; Akazawa, M.; Itoh, T.; Fujii, M.; Yamashita, K.; Inoue, K.; Itoh, T.; Shimomoto, H. $\pi$-AllylPdCl-Based Initiating Systems for Polymerization of Alkyl Diazoacetates: Initiation and Termination Mechanism Based on Analysis of Polymer Chain End Structures. Macromolecules 2012, 45, 6869-6877.

(27) Ihara, E.; Takahashi, H.; Akazawa, M.; Itoh, T.; Inoue, K. Polymerization of Various Alkyl Diazoacetates Initiated with $(\mathrm{N}$ Heterocyclic Carbene)Pd/Borate Systems. Macromolecules 2011, 44, 3287-3292.

(28) Franssen, N. M. G.; Reek, J. N. H.; de Bruin, B. Pd-Mediated Carbene polymerisation: Activity of Palladium(II) versus Low-Valent Palladium. Polym. Chem. 2011, 2, 422-431.

(29) Ihara, E.; Hiraren, T.; Itoh, T.; Inoue, K. Palladium-Mediated Polymerization of Cyclic Diazoketones. J. Polym. Sci., Part A: Polym. Chem. 2008, 46, 1638-1648.

(30) Ihara, E.; Kida, M.; Fujioka, M.; Haida, N.; Itoh, T.; Inoue, K. Palladium-Mediated Copolymerization of Diazocarbonyl Compounds With Phenyldiazomethane. J. Polym. Sci., Part A: Polym. Chem. 2007, 45, 1536-1545.

(31) Ihara, E.; Fujioka, M.; Haida, N.; Itoh, T.; Inoue, K. First Synthesis of Poly(acetylmethylene)s via Palladium-Mediated Polymerization of Diazoketones. Macromolecules 2005, 38, 2101-2108.

(32) Ihara, E.; Haida, N.; Iio, M.; Inoue, K. Palladium-Mediated Polymerization of Alkyl Diazoacetates To Afford Poly(alkoxycarbonylmethylene)s. First Synthesis of Polymethylenes Bearing Polar Substituents. Macromolecules 2003, 36, 36-41.

(33) de Bruin, B.; Budzelaar, P. H. M.; Gal, A. W. Functional Models for Rhodium-Mediated Olefin-Oxygenation Catalysis. Angew. Chem., Int. Ed. 2004, 43, 4142-4157.

(34) Hetterscheid, D. G. H.; Hendriksen, C.; Dzik, W. I.; Smits, J. M. M.; van Eck, E. R. H.; Rowan, A. E.; Busico, V.; Vacatello, M.; Van Axel Castelli, V.; Segre, A.; Jellema, E.; Bloemberg, T. G.; de Bruin, B. Rhodium-Mediated Stereoselective Polymerization of "Carbenes. J. Am. Chem. Soc. 2006, 128, 9746-9752.

(35) Noels, A. F. Carbene Chemistry: Stereoregular Polymers from Diazo Compounds. Angew. Chem., Int. Ed. 2007, 46, 1208-1210.

(36) Jellema, E.; Budzelaar, P. H. M.; Reek, J. N. H.; de Bruin, B. RhMediated Polymerization of Carbenes: Mechanism and Stereoregulation. J. Am. Chem. Soc. 2007, 129, 11631-11641.

(37) Pilar del Río, M.; Ciriano, M. A.; Tejel, C. From Olefins to Ketones via a 2-Rhodaoxetane Complex. Angew. Chem., Int. Ed. 2008, 47, 2502-2505.

(38) Jellema, E.; Jongerius, A. L.; Walters, A. J. C.; Smits, J. M. M.; Reek, J. N. H.; de Bruin, B. Ligand Design in Rh(diene)-Mediated "Carbene" Polymerization; Efficient Synthesis of High-Mass, Highly 
Stereoregular, and Fully Functionalized Carbon-Chain Polymers. Organometallics 2010, 29, 2823-2826.

(39) Franssen, N. M. G.; Remerie, K.; Macko, T.; Reek, J. N. H.; de Bruin, B. Controlled Synthesis of Functional Copolymers with Blocky Architectures via Carbene Polymerization. Macromolecules 2012, 45, 3711-3721.

(40) Walters, A. J. C.; Jellema, E.; Finger, M.; Aarnoutse, P.; Smits, J. M. M.; Reek, J. N. H.; de Bruin, B. Rh-Mediated Carbene Polymerization: From Multistep Catalyst Activation to AlcoholMediated Chain-Transfer. ACS Catal. 2012, 2, 246-260.

(41) Walters, A. J. C.; Troeppner, O.; Ivanović-Burmazović, I.; Tejel, C.; del Río, M. P.; Reek, J. N. H.; de Bruin, B. Stereospecific Carbene Polymerization with Oxygenated $\mathrm{Rh}$ (diene) Species. Angew. Chem., Int. Ed. 2012, 51, 5157-5161.

(42) Shimomoto, H.; Shimizu, K.; Takeda, C.; Kikuchi, M.; Kudo, T.; Mukai, H.; Itoh, T.; Ihara, E.; Hoshikawa, N.; Koiwai, A.; Hasegawa, N. Synthesis of Polymers with Densely-Grafted Oligo (Ethylene Glycol)s by Pd-Initiated Polymerization of OxyethyleneContaining Diazoacetates. Polym. Chem. 2015, 6, 8124-8131.

(43) Shimomoto, H.; Itoh, E.; Itoh, T.; Ihara, E.; Hoshikawa, N.; Hasegawa, N. Polymerization of Hydroxy-Containing Diazoacetates: Synthesis of Hydroxy-Containing "Poly(substituted Methylene)s" by Palladium-Mediated Polymerization and Poly(ester-Ether)s by Polycondensation through $\mathrm{O}-\mathrm{H}$ Insertion Reaction. Macromolecules 2014, 47, 4169-4177.

(44) Katsumoto, Y.; Kubosaki, N. Tacticity Effects on the Phase Diagram for Poly(N-Isopropylacrylamide) in Water. Macromolecules 2008, 41, 5955-5956.

(45) Ray, B.; Okamoto, Y.; Kamigaito, M.i; Sawamoto, M.; Seno, K.I.; Kanaoka, S.; Aoshima, S. Effect of Tacticity of Poly $(\mathrm{N}$ Isopropylacrylamide) on the Phase Separation Temperature of Its Aqueous Solutions. Polym. J. 2005, 37, 234-237.

(46) Hirano, T.; Okumura, Y.; Kitajima, H.; Seno, M.; Sato, T. Dual Roles of Alkyl Alcohols as Syndiotactic-Specificity Inducers and Accelerators in the Radical Polymerization of N-Isopropylacrylamide and Some Properties of Syndiotactic Poly(N-Isopropylacrylamide). J. Polym. Sci., Part A: Polym. Chem. 2006, 44, 4450-4460.

(47) Franssen, N. M. G.; Ensing, B.; Hegde, M.; Dingemans, T. J.; Norder, B.; Picken, S. J.; Alberda van Ekenstein, G. O. R.; van Eck, E. R. H.; Elemans, J. A. A. W.; Vis, M.; Reek, J. N. H.; de Bruin, B. On the "Tertiary Structure" of Poly-Carbenes; Self-Assembly of $\mathrm{sp}^{3}$ Carbon-Based Polymers into Liquid-Crystalline Aggregates. Chem. Eur. J. 2013, 19, 11577-11589.

(48) Tokita, M.; Shikinaka, K.; Hoshino, T.; Fujii, K.; Mikami, J.; Koshimizu, N.; Sakajiri, K.; Kang, S.; Watanabe, J.; Shigehara, K. Thermotropic Behavior of Syndiotactic Polyethylenes with Alkyloxycarbonyl Side Chains. Polymer 2013, 54, 995-998.

(49) Koshimizu, N.; Aizawa, Y.; Sakajiri, K.; Shikinaka, K.; Shigehara, K.; Kang, S.; Tokita, M. Thermotropic Behavior of Syndiotactic Polymethylenes with $\omega$-[4-(trans-4-Pentylcyclohexyl)phenoxy]alkyloxycarbonyl Side Chains. Macromolecules 2015, 48, 3653-3661.

(50) Shikinaka, K.; Suzuki, K.; Masunaga, H.; Ihara, E.; Shigehara, K. Stiff and Hierarchical Chain Nature of Atactic and Stereoregular Poly(Substituted Methylene)s. Polym. Int. 2018, 67, 495-499.

(51) Zheng, X.; Tong, Z.; Xie, X.; Zeng, F. Phase Separation in Poly ( $N$-isopropyl acrylamide)/Water solutions I. Cloud Point Curves and Microgelation. Polym. J. 1998, 30, 284-288.

(52) Lessard, D. G.; Ousalem, M.; Zhu, X. X. Effect of the Molecular Weight on the Lower Critical Solution temperature of $\operatorname{Poly}(N, N$ diethylacrylamide) in Aqueous Solutions. Can. J. Chem. 2001, 79, $1870-1874$.

(53) Furyk, S.; Zhang, Y.; Ortiz-Acosta, D.; Cremer, P. S.; Bergbreiter, D. E. Effects of End Group Polarity and Molecular Weight on the Lower Critical Solution Temperature of Poly $(N$ isopropylacrylamide). J. Polym. Sci., Part A: Polym. Chem. 2006, 44, 1492-1501.

(54) Relationships between concentration and $M_{\mathrm{n}}$ and LCST have been described in other reports. Usually, the polymers that are compared have very similar PDI values. Whereas in some papers the PDI is not taken into consideration as a parameter which could be of influence on the LCST, ${ }^{55,56}$ others observed an influence of the PDI on the LCST behavior ${ }^{51}$ or found a minor role of the PDI on the LCST for polymers with high molecular weight. ${ }^{52}$

(55) Ihata, O.; Kayaki, Y.; Ikariya, T. Synthesis of Thermoresponsive Polyurethane from 2-Methylaziridine and Supercritical Carbon Dioxide. Angew. Chem., Int. Ed. 2004, 43, 717-719.

(56) Schild, H. G.; Tirrell, D. A. Microcalorimetric Detection of Lower Critical Solution Temperatures in Aqueous Polymer Solutions. J. Phys. Chem. 1990, 94, 4352-4356.

(57) Tong, Z.; Zeng, F.; Zheng, X.; Sato, T. Inverse Molecular Weight Dependence of Cloud Points for Aqueous Poly $(\mathrm{N}$ Isopropylacrylamide) Solutions. Macromolecules 1999, 32, 44884490.

(58) Toma, T.; Shimokawa, J.; Fukuyama, T. N,N'-Ditosylhydrazine: A Convenient Reagent for Facile Synthesis of Diazoacetates. Org. Lett. 2007, 9, 3195-3197.

(59) Tejel, C.; Ciriano, M. A.; Sola, E.; del Río, M. P.; Ríos-Moreno, G.; Lahoz, F. J.; Oro, L. A. Dimetallic Dioxygen Activation Leading to a Doubly Oxygen-Bridged Dirhodium Complex. Angew. Chem., Int. Ed. 2005, 44, 3267-3271. 